\title{
Estado e Sociedade Civil no Brasil: Uma Maltratada Relação?
}

\author{
Vera Lúcia Peixoto Santos Mendes *
}

\section{Introdução}

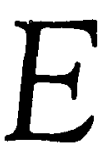

m fins do século XX, a crise do Estado tem sido assunto debatido em quase todo o planeta. Nestes debates, são apresentadas muitas causas e algumas soluções. Embora o diagnóstico seja comum aos diversos países, os modos de enfrentamento da(s) crise(s) diferem na Europa e nos EUA. O momento é de muitas incertezas, duvida-se até se a crise é só do Estado, se é uma crise econômica, ou de valores sociais. Não se pode, ao certo, delimitar a natureza da (s) crise(s).

No panorama internacional, Martins (1997) caracteriza a crise do Estado conforme se afigurou nos EUA e na Inglaterra, identificando alguns pilares recorrentes: colapso do desenvolvimentismo pós-guerra, o fim de Bretton Woods; crises do petróleo, de liquidez e a instabilidade do mercado financeiro internacional, os novos requisitos de integração competitiva decorrentes da globalização; crise do welfare state keynesiano; disfunções burocráticas ou crise do modo de implementação estatal dos serviços públicos e a ingovernabilidade decorrente da sobrecarga fiscal, do excesso de demandas e da crise de legitimidade.

No contexto americano, as respostas à crise caracterizam-se por um hibridismo, de tendência gerencialista e cunho empresarial, típico do reinventing government e, por outro lado, ortodoxa, do tipo ideal burocrático weberiano. Já na Inglaterra, optou-se por três tipos de soluções: o gerencialismo puro, o consumerism e o Public Service Oriented (PSO).

* Prof da UFBA, Mestre em Administração, Doutoranda em Administração NPGA/UFBA 
gerencialismo puro foi mais desestatizante do que racionalizador; o consumerism consistiu numa reorientação do gerencialismo puro, voltando-se para a racionalização e a satisfação das necessidades dos cidadãos/ consumidores dos serviços públicos, adotando, para tanto, a estratégia da qualidade. Este modelo apresentou como problema básico:

“...o conflito entre interesses do consumidor e do cidadão, que envolve limites na cobrança de resultados (accountability), questões de eqüidade e efeitos perversos da competitividade - como os efeitos de soma zero." (Martins, 1997, p. 68)

O gerencialismo e o consumerism baseavam-se em "como" e o PSO baseava-se no "que" fazer e, assim, este priorizou a revalorização da política na definição das finalidades estatais, o aumento da accountability, participação, transparência, eqüidade e justiça, privilegiando a esfera pública como locus de aprendizagem social e a defesa do aprimoramento da cultura cívica do cidadão. Este modelo, ao tempo em que procurou retomar o conceito de público, não abandonou a tecnologia gerencial desenvolvida nos modelos anteriores (Abrucio, 1996, apud Martins, 1997). Observa-se que, nos modelos ingleses, a questão da cidadania é preservada, na medida em que, no plano operativo, foram propostos reajustes ao serem detectados conflitos de interesses entre consumidor e cidadão.

Independente da natureza da crise, as relações entre Estado e sociedade civil têm sofrido alterações. Neste trabalho, serão discutidas essas relações, a partir de suas distintas concepções e em diferentes momentos históricos. Tal iniciativa se justifica à medida que tenta responder às seguintes questões:

- historicamente, como vem-se dando a relação entre Estado e sociedade civil?

- como determinados segmentos sociais percebem a cidadania e os direitos dos cidadãos no Brasil?

Para tanto, parte-se dos seguintes pressupostos:

- numa sociedade democrática, Estado e sociedade civil são um todo indivisível, de modo que as organizações públicas sentem a pressão do 
ambiente externo e se amoldam na tentativa de se espelhar nas forças competitivas do mercado;

- a eficiência que se busca no Estado contemporâneo só se concretizará se for referida a um padrão que determine suas atribuições essenciais e, sobre isso, no Brasil parece ainda não haver um consenso;

- um Estado que restringe, ao máximo, suas intervenções no espaço das interações sociais pode ter a sua legitimidade questionada.

Para compreender as relações entre Estado e sociedade, parte-se de uma breve abordagem das teorias mais relevantes sobre o Estado, sua formação e funções em diferentes momentos históricos, chegando-se ao momento atual em que, ante a(s) crise(s), busca-se um novo padrão de Estado. Discutem-se noções de cidadania e do direito a partir das concepções do Estado liberal clássico e do Estado Provedor, até os dias atuais em que o conceito de cidadania tem-se ampliado e em que têm sido incorporados os dilemas contemporâneos. Finalmente, são apresentados resultados de um estudo empírico, com uma amostra de usuários de serviços públicos, sobre o entendimento de cidadania e dos direitos dos cidadãos no Brasil. Estudos sobre cidadania têm contribuído para ampliar os conhecimentos sobre a expansão dos direitos civis, políticos e sociais e para a reformulação de políticas. públicas

\section{Fundamentos para compreender as relaçôes entre Estado e sociedade civil}

O conceito de Estado não é estático, entretanto, pode-se dizer que, de sua origem até os dias atuais, prevalecem alguns aspectos como a questão militar, a existência de território e povo. Segundo vários autores, Estado não é um conceito universal e serve somente para indicar e descrever uma forma de ordenamento político que surge na Europa a partir do século XIII. Do período compreendido entre 3000 a C. até os dias atuais, encontram-se diferentes formas de sociedade e de Estado. Em seus estágios evolutivos, Estado e sociedade passaram da forma antiga (3000 a C. ao séc. V d. C.) para a feudal $(700-800 \mathrm{~d}$. C. ao séc. XV) e desta para o Estado e sociedade por categorias (séc. XVI - séc. XVII). O surgimento da sociedade civil e o do Estado burocrático nacional vão-se dar no século XVII (Baiardi, 1996). 
O surgimento da sociedade civil, no sentido de civilizada e não de civitas (Estado antigo), só se faz plenamente no século XVII quando: “...no plano econômico, se estabelecem as livres relações de mercado sob a égide da propriedade privada e quando, no plano político, se desenvolve uma subjetividade autônoma em relação à família e ao Estado, contemplando direitos individuais e pleiteando sua titularidade plena" (Baiardi, 1996, p. 41).

A sociedade civil é a esfera das relações entre indivíduos, grupos e classes, situada externamente às relações de poder que caracterizam as instituições estatais. Deste modo, é na sociedade civil que ocorrem os conflitos para o Estado administrar. Nem sempre o entendimento de sociedade foi este, e, da mesma forma que o conceito de Estado, o conceito de sociedade sofreu modificaçōes ao longo do tempo.

Com Thomas Hobbes (1588-1679), começa a surgir uma teoria do Estado moderno, segundo a qual, quando os homens primitivos vivem no estado natural, ou seja, na condição de animais, eles se atiram uns contra os outros, pelo desejo do poder e propriedade (Gruppi, 1980). Dada a capacidade de destruição mútua, fazia-se necessária a existência de um contrato. Esse contrato criou o Estado absoluto e, através deste instrumento, dá-se a transferência, para o Estado de todos ou de alguns direitos, que o homem possuía no estado de natureza. Assim, o homem natural se transformou em homem civil ou cidadão. Atualmente, através do mesmo instrumento, o Estado repassa algumas de suas funções para o mercado, ampliando, deste modo, o papel do consumidor.

A filosofia política do jusnaturalismo é o ponto de partida para compreender a transferência do direito natural para o direito estatal. A partir do jusnaturalismo, nasce o conceito de cidadão e, nesse momento, cessa inteiramente o homem natural (Bobbio \& Bovero, 1987). A doutrina jusnaturalista do Estado não é uma teoria racional do Estado, mas sim uma teoria do Estado racional. Segundo os jusnaturalistas, o Estado é construído como ente da razão por excelência, entidade única, na qual o homem realiza plenamente sua natureza de ser racional. No estado de natureza, as paixões triunfavam sobre a razão. $O$ ato específico através do qual se explicita a racionalidade do Estado é a lei, entendida como norma geral e abstrata, produzida por uma vontade racional. Os jusnaturalistas não elaboraram uma teoria do Estado, no entanto, a denominada escola do direito natural 
deu uma importante contribuição para o entendimento da estrutura burocrática do Estado, o que se faz necessário para viver em liberdade, em uma sociedade de desiguais.

Em resumo, foi na Inglaterra durante o século XVII, que se deu a transformação dos súditos em cidadãos. Com a revolução liberal, houve um acordo entre a monarquia e a aristocracia de um lado, e a burguesia de outro, ocasionando o surgimento de normas parlamentares e a condução do Estado fundada numa declaração dos direitos do parlamento. Na sociedade burguesa, Estado (poder político) e sociedade civil (conjunto de relações econômicas) são separados. Na sociedade civil, existe a transmissão de propriedade mas não de poder político. Ao Estado cabe garantir e tutelar o livre-arbítrio da propriedade.

Com Hegel (1770-1831), reestabelece-se a distinção entre Estado e sociedade civil formulada no começo do século XVII, pondo o Estado como fundamento desta e da família. Para ele era o Estado que fundava a sociedade civil. Posteriormente, Marx vai afirmar que é a sociedade civil que formata o Estado, o seu surgimento e a natureza de suas leis. De acordo com a visão marxista não é o Estado que determina a estrutura econômica e, sim, o contrário. O Estado é parte essencial da estrutura econômica porque a garante, ou seja, é a superestrutura. Assim como o Estado escravista garantiu a reprodução da escravatura, o Estado capitalista garante o domínio das relações de produção capitalistas, a reprodução ampliada do capital e a acumulação. Desta forma, a crise do Estado afeta a economia.

O Estado não existiu sempre, mas quando surge se seculariza; em cada oportunidade, age como ente racional por excelência e como agente que garante o interesse coletivo (Bobbio \& Bovero, 1987). O termo sociedade civil também tem sofrido alterações e ampliado a sua compreensão, à medida que, além de ser o locus onde se dão as relaçôes econômicas, temse tornado símbolo de solidariedade social. Um termo que era visto com suspeição pelos pós-hegelianos críticos, passou a ser visto como algo positivo, sinônimo de civismo e democracia. Neste sentido, sociedade civil é definida como organização de interesses materiais e ideais, e Estado, como organização da autoridade (Reis, 1995).

A depender do período histórico e das concepções teóricas dominantes, a função do Estado modifica-se, indicando que o tempo passa e as relações entre Estado e sociedade civil são, de alguma forma, mantidas. Es- 
tado e sociedade são um todo indivisível e interdependente, de modo que parece não ser possível resolver a crise do Estado pela via do aparelho do Estado sem remeter a uma crise maior, a do modo de produção.

\section{O papel do Estado coritemporâneo na vida social}

A necessidade de discutir sobre este assunto surge da indefinição, ou mesmo da falta de consenso, quanto ao papel do Estado na condução dos direitos sociais, ou da crise normativa do Estado contemporâneo. Para introduzir o debate, podem-se alinhar as funções do Estado segundo duas concepções: a liberal, que restringe suas funções à regulação do mercado e à manutenção da ordem, e a de inspiração socialista, que demanda do Estado o papel intervencionista, com políticas distributivas, corrigindo iniqüidades sociais, protegendo a vida em sociedade, além da execução de políticas regulatórias e de segurança

A funçāo principal do Estado protetor clássico era resguardar os indivíduos e suas posses dos riscos que os ameaçavam. Seguindo esta racionalidade, o Estado Providencial legitima o Estado Protetor, devendo. se entender os direitos sociais como extensão dos direitos civis e políticos. Tornado obsoleto o conceito de providência divina, caberia ao Estado reparar as desigualdades sociais. Deste modo, o Estado Moderno, na forma de Estado protetor clássico, constitui o indivíduo como categoria econômica básica e este indivíduo, ao conquistar sua autonomia, libera-se das estruturas comunais e profissionais que o assistem e o limitam, e passa a demandar políticas sociais de cunho universalista.

Considerando-se que as necessidades são ilimitadas, o atendimento destas demandas requer uma estrutura burocrática estatal muito comple. xa, o que levará a uma crise financeira do Estado. Entendida desta forma, a crise contemporânea do Estado resulta do seu sucesso, pois é o fato de o Estado Providencial ter contribuído para a redução de desigualdades sociais que questiona, como objetivo consensual, o igualitarismo que está na base de suas políticas (Oliveira, 1997).

No âmbito do liberalismo, o princípio de "responsabilidade individual" está presente na constituição da sociedade, partindo do pressuposto de que todos os indivíduos são livres e dotados de razão. Rousseau subverteu este postulado, ao propor que não é o indivíduo, mas a sociedade, o sujeito 
de imputabilidade. $O$ direito natural fundamental é a liberdade e não a razão. A liberdade se define pela adesão à lei formulada pelo homem. De acordo com esta visão, em sociedade, o homem só poderá ser regido pela lei que emane da vontade geral, pois tal generalização é o critério de racionalidade da própria lei. Deste modo, todos os direitos positivos são direitos sociais (Strauss, 1954, apud Oliveira, 1997). A natureza não se presta mais para definir o que é justo ou injusto, isto faz-se a partir do conhecimento sociológico.

O esforço de conciliação efetivado no interior do diagrama liberal, no sentido de equacionar esta "questão social", teve como um de seus resultados a postulação de uma visão solidária de sociedade, que ressurge de tempos em tempos, inclusive no momento atual. Durkheim fez uma analogia da relação indivíduo-sociedade com órgão-organismo. Concebendo a sociedade como "coisa", o indivíduo recebe da sociedade sua posição e regulação. Deste modo, Durkheim estabeleceu um caráter cientifico à noção de solidariedade, retirando a conotação religiosa que limitava seu raio de influência. Seu fundamento é a divisão social do trabalho que diferencia os indivíduos e produz os elos que constituem o tecido social. Para Durkheim, solidariedade é algo que existe em si. Uma perspectiva dessa ordem implica uma crítica radical ao princípio liberal de justiça (Oliveira, 1997). Ao tomar-se a sociedade como entidade que tem sua própria existência, que não se reduz ao somatório de indivíduos, pode-se pensar nos males produzidos pela vida em sociedade. Assim, assume-se que, no processo de produção de riquezas, alguns segmentos arcam com maiores custos sociais, passando a ser vistos como sujeitos portadores de direitos sociais. Aqui estaria o enigma do Estado Providencial e da universalidade.

$\mathrm{Na}$ concepção liberal do Estado de Direito, o "sujeito da lei" é o indivíduo que, livremente, se faz representar por grupos de interesses, partidos políticos ou associações que irão movimentar as instâncias de jurisdição, em nome dos direitos do cidadão. Esse conceito de "sujeito da lei" pode ser questionado, pois, enquanto fundamento da legitimidade da lei, substitui-se o "sujeito da lei" pelo conceito de norma, capaz de conferir uma legitimidade ao direito e assim distinguir a legalidade da legitimidade.

Legalidade e justiça podem ser consideradas noções éticas fundamentais e não determinadas, situando-se na esfera do Estado a garantia da legalidade. Já o termo legitimidade possui dois significados, um genérico e 
outro específico. $O$ genérico tem o sentido de justiça ou racionalidade que estaria situada na esfera da sociedade civil. $O$ específico é usado na linguagem política como sendo um atributo do Estado, que consiste na presença, em uma parcela significativa da população, de um grau de consenso capaz de assegurar a obediência sem a necessidade de recorrer ao uso da força, a não ser em situações esporádicas (Bobbio et. al., 1986).

No que se refere ao papel do Estado, a visão liberal clássica tem como um de seus pilares o direito natural moderno, doutrina que confere valor e coerência às suas proposições acerca do exercício legítimo do poder estatal, com base no axioma da existência dos direitos inalienáveis do indivíduo. Já o Estado Providencial opera com o conceito de direitos sociais como núcleo estruturante de seu princípio de justiça. $O$ direito e a justiça trazem de modo implícito as idéias de acordo e proporcionalidade. O Estado de direito é aquele que garante a lei natural de seu pacto fundador.

A idéia de normalidade é essencial quando se discute o Estado Providencial, seu funcionamento enquanto instrumento de justiça social e tecnologia do seguro social. Mas a norma não fala por si e necessita sempre de um intérprete. $O$ Estado Providencial não pode se legitimar somente na constatação da norma, pois, se a norma traduz uma hegemonia de uns sobre os outros, esta hegemonia é sempre precária.

Para muitos autores, o valor da norma está no consenso. Assim, como valorizá-la sem remeter aos indivíduos que a formam? Seria necessário imputar aos indivíduos que veiculam suas opiniões os mesmos atributos de racionalidade e liberdade que constituem o "sujeito da lei" no diagrama liberal. A linguagem dos direitos individuais não pode prescindir de uma concepção do sujeito que o torne responsável por suas escolhas, pois são estas que conferem aos direitos, de que é portador, o caráter de fundamento da legitimidade do poder. Retomar a sociedade como constituinte do sujeito, põe em cheque o princípio da responsabilidade pois altera o significado da liberdade humana, postulado pela linguagem liberal (Oliveira, 1997).

Como ficariam os direitos sociais ante o novo modelo de administração pública? Prevaleceria a lógica do Estado protetor clássico? O mercado se encarregaria de suprir as necessidades daqueles cuja propriedade é apenas a força de trabalho? Em tempos de crise, mesmo esta mercadoria necessita do Estado Providencial para se realizar no mercado. Aliás, esta é a mercadoria mais importante a demandar das políticas públicas ações efi- 
cazes, ao tempo em que se internacionaliza o capital mas não se internacionaliza a mão-de-obra, principalmente nos Estados periféricos, com graves problemas estruturais.

A noção de justiça, exceto como virtude individual, pode estar sendo usada de modo impróprio e, conseqüentemente, a legitimidade de um Estado que restringe ao máximo suas intervenções no espaço da interação social pode ser questionada. Isso expressa uma posição mais coerente em relação ao poder concedido ao Estado e adota a idéia dos direitos de cidadania como direitos individuais. A pretensão de legitimidade do Estado Providencial pode ser criticada pois o princípio de justiça social, para sua efetivação, requer sempre um leitor privilegiado, que detalhe os mecanismos que idealmente assegurariam a cada qual sua parte devida (Oliveira, 1997).

Tanto no diagrama liberal quanto nas concepções do Estado Providencial, a esfera de formulação dos direitos sociais está impregnada de holismo, que retira do campo a coerência necessária. Também é preciso requalificar o que se entende por "sujeito da lei". Há uma linguagem que associa os direitos ao indivíduo. O sujeito pode ser definido como um indivíduo autônomo ou uma representação, que necessita de outros que o constituem em determinado contexto. Assim, o papel do Estado contemporâneo deverá referir-se à conformação desse contexto na constituição do sujeito coletivo e na administração de demandas sociais, mas, sobre isso, parece ainda não haver um consenso.

\section{Estado e cidadania}

$\mathrm{Na}$ discussão da relação entre Estado e sociedade civil, cidadania é um dos conceitos centrais. O surgimento dos Estados Nacionais, com a transição do feudalismo para o capitalismo, teve como corolário o reconhecimento do status de cidadão ao povo, implicando no estabelecimento de uma pauta de direitos e deveres entre o cidadão e o seu Estado (Teixeira, 1987). Neste sentido, ter o status de cidadão é ser um legítimo portador de direitos e obrigações. Outra recorrente visão sobre cidadania relaciona-se à identidade e deriva da fusão de nação e Estado que, nos últimos dois séculos, tomou lugar e uniu os princípios de autoridade e solidariedade (Reis, 1997).

No que se refere à origem do conceito de cidadania, as mais importantes fontes estão nas religiões antigas, na civilização grega e no Império 
Romano. $\mathrm{Na}$ antigüidade grega, igualdade e liberdade adquiriram significado político no contexto da polis. Cidadania tem sido uma palavra- chave no campo da ciência política e é definida como política pública no plano da instrumentação estratégica (Demo, 1992). Enquanto fenômeno político possui um lado emancipatório ou ecônomico-produtivo e outro participativo, o qual pressupõe a existência da democracia. A emancipação é entendida como a capacidade de efetivar projeto próprio de desenvolvimento.

Um dos requisitos para o exercício da cidadania é o entendimento da democracia como valor maior e desta, enquanto locus de articulação das mediações entre Estado e sociedade. Isto posto, a cidadania expressa uma mediação que articula o conjunto de uma nação ao Estado representativo, assegurando-lhe a legitimidade necessária ao exercício do poder.

\section{Cidadania na contemporaneidade social e no contexto brasileiro}

Nos diferentes enfoques para a abordagem da cidadania, Benevides (1994) busca, na Revolução Francesa, as raízes da idéia de cidadania e apresenta duas visōes: progressista e conservadora. A primeira, ao discriminar os cidadãos em classes de cidadania, acaba reforçando a desigualdade, mas, ao estimular a participação social e política, constitui-se no que denomina de cidadania ativa. A segunda considera os direitos como concessões, predominando relações patrimonialistas e clientelistas entre Estado e sociedade. Os direitos são entendidos como privilégios, ou benesses concedidas pelo Estado a poucos indivíduos, compreendendo o que denomina de cidadania passiva ou outorgada pelo Estado. Freqüentemente, observa-se uma tensão entre as imagens de cidadão: uma enfoca o ideal republicano, retratando-o como portador de virtudes, orientado para o mundo público; e a outra concebe a cidadania como concessão de direitos, que vê o cidadão como um consumidor, devendo, assim, refugiar-se no mundo privado.

Uma breve análise das concepções teóricas sobre cidadania, de importantes autores do século XIX, realizada por Reis (1997), revela diferentes visões, com implicações para o desenvolvimento do conceito nos dias atuais. Para Marx, a cidadania era uma forma de alienação burguesa, e, centrando sua análise nas formas legal e política de participação, acreditava que o status de cidadania ocultava as reais fontes de exclusão social. 
Para Tocqueville, a emergência do cidadão foi uma conseqüência da eqüidade. Na visão de Weber, o desenvolvimento da cidadania resultou de um processo de afirmação da autonomia das cidades e das relaçōes entre os países. Este enfoque concebe a cidadania enquanto identidade.

No século XX, a principal contribuição no campo teórico vem de Marshall e sua tentativa de formular uma seqüência histórica e progressiva que confere ao seu discurso as características de uma teoria geral da mudança social (Reis, 1997). Na sua visão, a construção da cidadania e a constituição dos direitos podem ser caracterizados como um processo histórico, lento e seqüenciado, iniciando-se no século XVIII com a implantação dos direitos civis, seguida da conquista dos direitos políticos no século XIX e dos direitos sociais no século XX. Direitos civis significam liberdade individual, de falar, pensar e acreditar, o direito à propriedade, à realização de contratos e o direito à justiça. Direitos políticos correspondem ao direito de participar do poder político como membro de uma sociedade, investido de autoridade política ou como eleitor. Os direitos sociais são definidos como a extensão do bem-estar econômico e social, necessários para viver uma vida civilizada, estando de acordo com os padrôes prevalecentes na sociedade (Marshall, 1967).

A visão de Marshall tem sido amplamente debatida e alvo de muitas críticas quanto: ao fato de a narração ser em um contexto inglês, não podendo assim se generalizar; sua visão evolucionista; a maneira como relaciona classe e cidadania; à percepção da interação entre direitos sociais e industriais; à omissão do impacto das disputas internacionais; à ausência de uma discussão sobre preocupaçōes das minorias, dos efeitos da migração internacional, da relação entre cidadania e direitos humanos e sua incapacidade de prever a globalização.

Reis $(1988,1997)$ traça uma tipologia que serve tanto para sociedades desenvolvidas como em desenvolvimento, tratando a imagem de nação como uma coleção de indivíduos ou como indivíduos coletivos. Tal escolha está na raiz do capitalismo autoritário, cuja ênfase sobre o indivíduo coletivo significa um obstáculo aos direitos civis e políticos, enquanto os direitos sociais tornam-se uma dádiva das autoridades.

Embora sejam uma conquista deste século, os direitos sociais vêm perdendo espaço na esteira das modificações das relações entre Estado e sociedade civil. Observa-se que, independente de assumir uma posição mais 
estatizante ou liberal, as formas de prestação de serviços pelo Estado têmse pluralizado. Atualmente, uma relevante dimensão da cidadania se refere às questões das minorias, cujo maior desafio tem sido conciliar a direção universalizante, que a cidadania adquiriu na concepção moderna, com os reclamos pelos direitos de preservar as diferenças, enfatizando-se a afirmação das diferenças como uma maneira de assegurar a eqüidade. Nesta linha de raciocínio, têm-se construído estratégias como sistema de quotas, políticas para populações-alvo, etc. Entretanto, essas estratégias têm sido criticadas por diluir a solidariedade e a mobilização das massas, solapando, deste modo, o conflito capaz de mudar as iniqüidades.

No Brasil, com a Constituição de 1824, implantaram-se, ao mesmo tempo, os direitos civis e políticos, como uma iniciativa do Estado e em uma sociedade escravocrata. Assim, a ausência de espírito cívico constituise em uma das heranças da escravidão (Carvalho, 1992, apud Pinho et al., 1997). Observa-se aqui uma falta de sincronia entre o tipo de Estado e sociedade civil.

$\mathrm{Na}$ Constituição de 1891, a exigência de alfabetização para o exercício dos direitos políticos retirou do texto imperial a obrigação do governo de dar instrução primária, excluiu os pobres e aumentou, ainda mais, a fragmentação da cidadania. Deste modo, foi-se formando uma noção de cidadania distanciada das condições de existência da população brasileira, em uma sociedade marcada por desigualdades, constituindo-se uma cidadania para as minorias que podem organizar-se e que possuem os recursos materiais (Pinho et al., 1997

Com a constituição de 1988, embora denominada de "constituiçãocidadã", verifica-se no plano operacional, muitas vezes, a exclusão do acesso a serviços essenciais na manutenção da vida. Não se pode negar no entanto que, a partir da década de 90 , aumentaram as estruturas que asseguram os direitos do consumidor.

\section{Desenvolvimento do estudo empírico}

Foram entrevistados 2.401 usuários, em nove centros municipais de saúde de Salvador, no período de janeiro a março de 1998 . O instrumento de coleta de dados apresentava questões fechadas e abertas e foi autoaplicável, com exceção para os analfabetos, aos quais o entrevistador per- 
guntava e anotava as respostas. Na distribuição das características da amostra, predominaram: quanto ao gênero - sexo feminino (79\%); faixa etária, 17 a 30 anos $(46,2 \%)$ e 21 a 40 anos $(29,7 \%)$; grau de escolaridade - $1 \%$. Grau incompleto $(56,1 \%)$; etnia - negros $(35,9 \%)$, mulatos com ascendentes negros $(35,2 \%)$ e brancos $(16,1 \%)$ e renda familiar - de um a cinco salários mínimos $(56,9 \%)$ e menos de um salário mínimo $(24,6 \%)$. Quanto aos serviços demandados, as maiores freqüências foram para médico clínico $(57,1 \%)$ ginecologista $(42,2 \%)$ e pediatra $(42,2 \%)$, além de programas de pré-natal $(13,4 \%)$ e vacinação $(43,1 \%)$ Trata-se de uma amostra composta, na sua maioria, por mulheres em fase reprodutiva, negras, com baixa escolaridade, limitada capacidade de consumo e com uma demanda por serviços de baixa composição tecnológica. Para uma clientela com estas características, os serviços públicos são a única escolha. Deste modo, interessava conhecer o que ela define como cidadania e o entendimento sobre os direitos sociais no Brasil, considerando-se a Constituição de 1988, principalmente no que refere ao Art. 196.

\section{Resultados: Entendimento dos usuários de serviços públicos de saúde sobre o que é ser cidadão e quais os direitos de cidadania no Brasil}

O entendimento da cidadania enquanto qualidades pessoais positivas e autonomia e riqueza representa, na pesquisa, a primeira posição depois das respostas não sabem / não respondem e outras (Gráfico 1). Estes resultados encontram respaldo no poder concedido ao Estado e na idéia dos direitos de cidadania como direitos individuais, cujas raízes estão na filosofia jusnaturalista. Do mesmo modo, ao responderem à questão quais os direitos dos cidadãos no Brasil, o direito civil representa $8,3 \%$ do total das respostas, ou seja, ocupa a terceira posição (Gráfico 2). Isso quer dizer que, embora ser cidadão signifique ter direitos individuais, acesso a propriedades, bens, etc, os direitos de cidadania no Brasil mais citados não são os civis e políticos, mas os sociais (Gráfico 2). Para esta questão, também se encontram maiores freqüências de respostas não sabe / não responde e outras, que somam $54,4 \%$ (Gráfico 2). A expressão negativa do direito $(6,6 \%)$ também é um achado importante. Nesta categoria, encontram-se 
respostas como: "direito nenhum, pobre não tem direito a quase nada, só ao sofrimento; direito de ser passado para trás".

\begin{tabular}{|l|l|}
\hline G ráfico 1 - Percentuais de respostas sobre o entendimento de \\
cidadania. SSA, 1998.
\end{tabular}

De acordo com o Gráfico 2, observa-se a existência de respostas associadas, ou seja, que incluíram direitos civis, políticos e sociais e, de acordo com a visão evolucionista traçada por Marshall, poderiam ser consideradas respostas mais completas. Outro aspecto que se destaca no Gráfico 2 é a baixa freqüência dos direitos políticos $(0,9 \%)$. Isso pode estar relacionado com as características da amostra e, de certa forma, representa o distanciamento dos direitos políticos do cotidiano dos entrevistados. Embora, no País, a democracia política esteja instalada, a fragilidade dos partidos e a forma clientelista de exercer os direitos políticos são problemas a serem enfrentados.

Gráfico 2 - Percentuais de respostas sobre direitos dos cidadãos no Brasil. SSA, 1998.

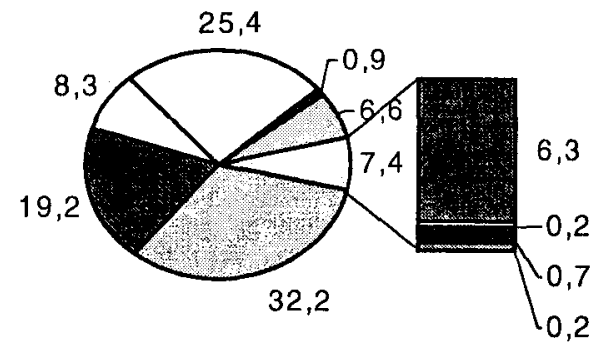

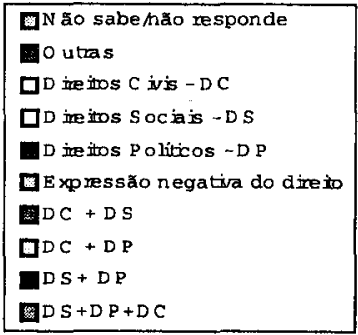


A análise da Tabela 1 revela que proporção de respostas não sabe e não responde é maior para as mulheres $(45,3 \%)$ e esta diferença é estatisticamente significante, denotando que estas têm mais dificuldades de formular um definição para a cidadania. Os homens expressam o entendimento de cidadania como direitos e deveres perante a outros, Estado e sociedade, em maiores proporçōes, o que também apresenta significância estatística (Tabela 2).

\section{Tabela 1 - Distribuição percentual de respostas sobre cidadania por gênero e respectivos intervalos de confiança (95\%). Salvador, 1998.}

\begin{tabular}{l|cccccc}
\hline \multicolumn{1}{c|}{ Resposta / Gênero } & LI & $\begin{array}{c}\text { Masculino } \\
(\mathrm{N}=504)\end{array}$ & LS & LI & $\begin{array}{c}\text { Feminino } \\
(\mathrm{N}=1847)\end{array}$ & LS \\
\hline Não sabe/Nä́o iesponde & 29,7 & 31,5 & 33,4 & 43,3 & 45,3 & 47,3 \\
Qualidades pessoais positivas & 21,7 & 23,4 & 25,2 & 18,8 & 20,3 & 22 \\
Autonomia e riqueza & 4,1 & 5 & 5,9 & 2,9 & 3,6 & 4,5 \\
Direitos e deveres perante a outros, & 27 & 28,8 & 30,6 & 18,8 & 20,4 & 22,1 \\
Estado e sociedade & 10,1 & 11,3 & 12,2 & 9,1 & 10,3 & 11,6 \\
Outras & & & &
\end{tabular}

LI = Limite Inferior; $\mathbf{L S}=$ Limite Superior

Tabela 2 - Distribuição percentual de respostas sobre os direitos dos cidadão no Brasil por gênero e respectivos intervalos de confiança (95\%). Salvador, 1998.

\begin{tabular}{l|cccccc}
\hline \multicolumn{1}{c|}{ Resposta /Gênero } & LI & $\begin{array}{c}\text { Masculino } \\
(\mathrm{N}=504)\end{array}$ & LS & LI & $\begin{array}{c}\text { Feminino } \\
(\mathbf{N = 1 8 9 7 )}\end{array}$ & LS \\
\hline Não sabe/não responde & 20,8 & 22,4 & 24,6 & 33 & 34,9 & 36,8 \\
Direitos Civis - DC & 9,9 & 11,1 & 12,6 & 6,5 & 7,5 & 8,7 \\
Direitos Sociais - DS & 24,6 & 26,4 & 28,2 & 23,4 & 25,1 & 26,9 \\
Direitos Políticos - DP & 0,5 & 0,8 & 1,3 & 0,6 & 0,9 & 1,4 \\
Expressão negativa do direito & 9,7 & 10,9 & 12,2 & 4,7 & 5,5 & 6,5 \\
Outras & 20,8 & 22,4 & 24,2 & 16,8 & 18,3 & 19,9 \\
DC + DS & 0,07 & 0,2 & 0,5 & 0,04 & 0,2 & 0,4 \\
DC + DP & 3,8 & 4,6 & 5,5 & 5,8 & 6,8 & 7,9 \\
DS+ DP & 0,5 & 0,8 & 1,3 & 0,4 & 0,7 & 1,1 \\
DS + DP + DC & 0,2 & 0,4 & 0,8 & 0.004 & 0,05 & 0,3 \\
\hline
\end{tabular}

LI = Limite Inferior; LS = Limite Superior 
De acordo com dados da Tabela 2, as proporções de respostas não sabem /não respondem à questão quais os direitos dos cidadãos no Brasil foram maior para as mulheres e isto foi estatisticamente significante, ou seja, o desconhecimento sobre o direitos é maior entre o grupo de mulheres. Dentre os direitos citados, apresentaram significância estatística nas diferenças entre os gêneros e com maiores proporções para os homens, os direitos civis, a expressão negativa do direito e outras. Também foi estatisticamente significante mas com maior proporção de respostas de mulheres a associação direitos civil e político (Tabela 2).

Parte da contribuição para o debate sobre cidadania veio do feminismo crítico, da democracia liberal e isto gerou o conceito de cidadão universal na teoria, mas realmente nascido na esfera pública, derivada de valores masculinos. Por causa da identificação das mulheres com a esfera privada, doméstica, e da limitação de sua vida a este lugar, mesmo agora, tem havido dificuldade de qualificá-la como cidadã (Saxonhouse, 1985; Phillips, 1993, apud Chapman, 1995). A teoria do contrato social, apesar de enfatizar o universalismo, o individualismo e o consentimento dos governados, de fato reforça a exclusão da mulher (Paterman, 1988, apud Chapman, 1995). Alguns teóricos liberais assumem que mulheres foram naturalmente sujeitos subordinados, contratadas para o casamento, não têm papel cívico e, na prática, o "indivíduo" é o homem. Sem querer entrar no debate sobre a teoria feminista, estes dados apenas apontam nesta direção, revelando que, na prática, há um maior distanciamento das mulheres sobre cidadania e os direitos dos cidadãos no Brasil.

A Tabela 3 (em anexo) demonstra que o entendimento de cidadania por grau de escolaridade, os grupos de analfabetos, $1^{\circ}$. grau incompleto e $1^{\circ}$. grau completo apresentaram maiores proporções de respostas "não sabe / não responde", com diferenças estatisticamente significantes, ou seja, quanto menor o grau de escolaridade maiores as proporções destas respostas .Evidenciase que quanto mais aumenta o grau de escolaridade, maiores são as proporções de respostas de entendimento de cidadania como direitos e deveres perante outros, Estado e sociedade. Para essa questão, os grupos de analfabetos, 1ㅇ․

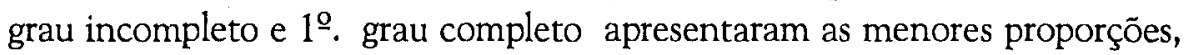
com diferenças estatisticamente significantes (Tabela 3).

$A$ análise do entendimento dos direitos do cidadão no Brasil por grau de escolaridade (Tabela 4, em anexo) denota que, quanto maior o 
grau de escolaridade, menores foram as proporções de respostas "não sabe / não responde", com diferenças estatisticamente significantes para os grupos com $1^{\circ}$. grau completo e incompleto e analfabetos. Estes dois últimos grupos apresentaram diferenças estatísticas para direito civil com proporções mais elevadas. Com relação aos direitos sociais, estes dois grupos e universitários apresentaram diferenças estatísticas; os primeiros para menos e o último para mais. Ou seja, os indivíduos de baixa escolaridade apresentaram baixas proporções de respostas em relação aos direitos sociais.

Em relação aos direitos políticos, a proporção de respostas para os analfabetos foi "zero". Embora seja facultado o voto ao analfabeto no País, nesta pesquisa o grupo respondeu como se não existissem direitos políticos. Para esta mesma questão, encontram-se diferenças estatisticamente significantes entre os grupos com $1^{\circ}$ e $2^{\circ}$ graus incompletos e $1^{\circ}$ e $2^{\circ}$ graus completos. Estes, como maiores proporções e aqueles, com menores. A expressão negativa dos direitos apresentou baixas proporções entre os analfabetos e mais elevadas entre o $2^{\circ}$ grau completo e incompleto, com diferenças estatísticas. Isto pode representar a expressão de insatisfações As respostas "outros" tiveram maiores proporçōes entre o grupo de $2^{\circ}$ grau e $1^{\circ}$ grau incompleto, com diferenças estatísticas entre estes e o grupo de analfabetos e $1^{\mathrm{O}}$ grau completo. Poucos indivíduos apresentaram respostas conjugadas (direitos sociais, políticos e civis), encontrando-se uma maior proporção de respostas que associam direitos civis e sociais (Tabela 4, em anexo).

Conforme análise de correspondência evidenciada na Figura 1, podese observar associação, na primeira dimensão, entre analfabetos (ANA), não sabem (NS) ou não respondem (NSR) o que é ser cidadão e quais os direitos dos cidadãos no Brasil, assim como uma associação positiva entre grau de escolaridade e entendimento dos direitos dos cidadãos, encontrando-se no extremo oposto, os universitários e entendimento dos direitos dos cidadão como direitos civis, políticos e sociais. Do ponto de vista da relação do cidadão com o Estado, isso implica em reforçar a manutenção da visão conservadora de cidadania, em que os direitos são tratados como concessões. A exclusão do acesso à educação faz com que o indivíduo seja incapaz de reconhecer-se enquanto sujeito portador de direitos, reduzindo, deste modo, a demanda por políticas públicas compensatórias.

Um olhar sobre a segunda dimensão da Figura 1, revela associação entre gênero masculino $(M)$, apresentar outras respostas (OU12) para os 
direitos dos cidadãos e entender a cidadania como qualidades pessoais positivas (QPP). Isto significa que, para os homens, a cidadania é um atributo do indivíduo, algo inerente à condição humana, do tipo "ser honesto, inteligente e ter respeito pelo próximo". Observa-se ainda haver associação entre entendimento dos direitos civis (DC) e de cidadania como autonomia e riqueza (CAR) e, como contra-ponto, há associação entre direito social (DS) e direito político (DP). Estas evidencias reforçam a visão de Reis (1997) que enfatiza a dicotomia entre uma nação enquanto reflexo de indivíduos coletivos ou enquanto coleção de indivíduos. A visão do direito civil como direito à liberdade, à propriedade, à realização de contratos, etc e a percepção de cidadania como autonomia e riqueza, localizam-se, neste estudo, muito próximas e encontram ressonância no diagrama político liberal. Do outro lado da Figura 1, estão associados direitos sociais e direitos políticos (DSDP) e ainda, escolaridade de segundo grau (SG e SGI) e entendimento de cidadania enquanto direitos deveres perante outros, Estado e sociedade (CDD), o que reafirma o exposto no parágrafo acima. O entendimento de cidadania e dos direitos dos cidadãos expressos neste trabalho, representam uma mediação que articula uma coleção de indivíduos.

Figura 1 - Análise multivariada de correspondência

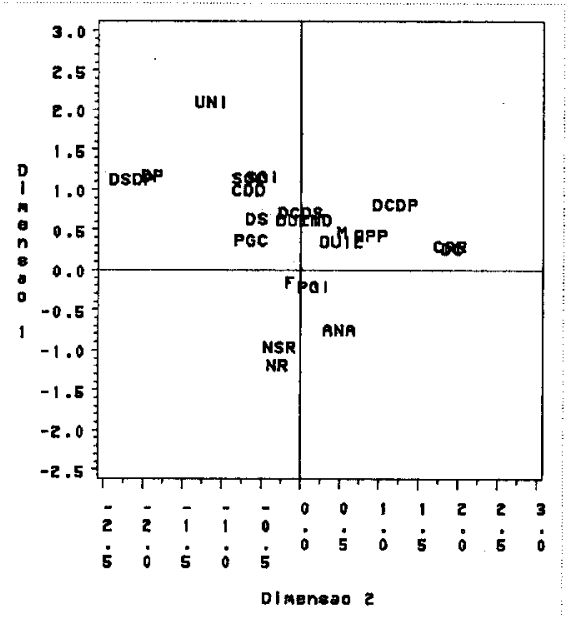




\section{À guisa de conclusão}

Este trabalho objetivou discutir as relações entre Estado e sociedade civil em diferentes momentos históricos, a partir de distintas concepções teóricas e de análise de dados empíricos, enfocando como conceitos básicos as noções de cidadania e dos direitos sociais no Brasil.

A descoberta da sociedade civil é produto do mundo moderno e surge, efetivamente, a partir dos elementos da propriedade e do Estado, desenvolvendo-se como locus das relações econômicas, sociais, ideológicas e religiosas, com formas de grupos, movimentos, associações e partidos. No contexto da(s) crise(s) do Estado, observa-se que as questōes da cidadania e da democracia têm-se redimensionado e adquirido importância cada vez maior, tanto no debate acadêmico como enquanto campo de pesquisa empírica. A amplitude do conceito de cidadania e a incorporação de novos enfoques retomam a idéia de progressividade trazida para o campo por Marshall. Isso, de certa forma, remove alguns resíduos teóricos, encapsulados no interior do pensamento conservador e aponta para a dinâmica que move as relaçōes Estado e sociedade, demonstrando que não é só um lado da equação que se reforma.

No passado, a tradição teórica marxista via a cidadania como parte do discurso liberal, competindo com o conceito de classe social. Hoje, esta corrente vê a cidadania associada ao conceito de movimento social, solidariedade e sociedade civil, de modo que a maioria dos que trabalham nessa perspectiva, enfoca o aspecto cívico da cidadania. O debate atual do conceito de cidadania tem reduzido a disputa entre o comunitarismo e o individualismo, porém recoloca a dicotomia entre as noções de cidadania: a que enfoca o status e a que privilegia a identidade e a noção de associação de idéias e sentimentos. O primeiro enfoque enfatiza o papel do Estado em assegurar o acesso aos direitos que têm o cidadão ao consumo. $O$ segundo confere primazia ao corpo de sentimentos comuns e que divide identidades usadas na identificação com a nação e no compromisso com os interesses coletivos.

Em uma sociedade como a brasileira, marcada por níveis elevados de desigualdade social e por um sistema social híbrido e multifacetado, composto de vazios institucionais, a ineficiência estatal, em termos de metas coletivas, torna-se perversa, aliando privação social e destituição 
política. São destituições que inviabilizam o pleno exercício da cidadania e o aprimoramento político da sociedade. Assim, para que possam ser exercidos os direitos de cidadania, interessa fortalecer as instituições partidárias e parlamentares, bem como os demais mecanismos de participação e incorporação de políticas.

O Estado brasileiro se revela incapaz de fazer valer seus ordenamentos legais nas várias categorias da estratificação social. Cuidar dos costumes políticos é uma obrigação da lei, que muitas vezes se faz inócua. A questão da justiça social não está equacionada. No momento em que se discute a reforma do Estado, as propostas apresentadas parecem não dar conta do padrão de Estado que se quer nem do que "deve ser", demonstrando assim a existência de vazios teóricos a serem preenchidos. Algumas destas propostas foram testadas em espaços geográficos mais providos de noções de cidadania e apresentaram problemas como o consumerism na Inglaterra, confundindo, em nível local, cidadão e consumidor. A aplicação indistinta de modelos, sem os devidos ajustes, poderá incorrer no risco de tornar cidadãos portadores de "cidadania menor" em consumidores de coisas que não são mercadorias e que, por isso, não podem ser trocadas no mercado mediante relações de troca, mesmo que possam ser consumidas por cada pessoa individualmente. Deste modo, a tentativa do Estado de resolver uma crise pode, nos países periféricos, estar gerando crises mais profundas e de mais difíceis soluções.

Os problemas enfrentados pela sociedade relacionam-se à competência e à eficiência da máquina estatal, aos aspectos ligados à sustentabilidade política das decisões e à legitimidade dos fins que se pretende alcançar por meio da ação governamental. Para tanto, parece que é imprescindível, no caso do Brasil, compatibilizar eficiência do Estado, aprimoramento da democracia e exercício da cidadania. São tarefas difíceis mas não impossíveis.

A baixa eficiência da administração pública brasileira expressa-se pela omissão do Estado no atendimento às necessidades fundamentais, na ausência de canais para expressão de direitos elementares e pela inexistência de políticas sociais efetivas. Assim, abre-se espaço para a insegurança, práticas sociais predatórias, surgimento de sistemas paralelos de poder e subversão às leis. Ante a crise de legitimidade, aprofunda-se o divórcio entre Estado e sociedade civil, esvaziam-se os direitos de cidadania, confundin- 
do-se cidadão e consumidor, contribuindo para manter, no País, uma maltratada relação entre Estado e sociedade civil.

\section{Nota}

Esta investigação recebeu o apoio financeiro da OPS/OMS.

\section{Referências bibliográficas}

BAIARDI, Amilcar. Sociedade e Estado no apoio à Ciência e à Tecnologia: uma análise histórica. São Paulo: Hucitec, 1996. 245p.

BENEVIDES, Maria Vitória de Mesquita. Cidadania e democracia. Lua Nova. São Paulo, n. 33, p.5-16, 1994.

BRASIL . MINISTÉRIO DA EDUCAÇÃO. Constituição da República Federativa do Brasil. Rio de Janeiro: FAE, 1989.

BOBBIO, N. BOVERO, M. Sociedade e Estado na filosofia política moderna. São Paulo: Brasiliense,. 1986.

DEMO, Pedro. Cidadania menor: algumas indicaçōes quantitativas de nossa pobreza política. Petrópolis: Vozes, 1992. 192p.

DINIZ, Eli. Crise, reforma do Estado e governabilidade: Brasil, 1985-95. Rio de Janeiro: Editora da Fundação Getulio Vargas, 1997. Cap. 5, p. 175-202. HEGEL, G.W.F. Princípios da Filosofia do Direito. Lisboa: Guimarães Editora, 1990.

MARSHALL, T. H. Cidadania, classe social e status. Rio de Janeiro: Zahar, 1967.

MARSH, D., STOKER G. (Eds) Theory and Methods in Political Science. Houndsmills e Londres: Macmillan, 1995.. Chapter 5:. The feminist perspective - Jenny Chapman. p.19-133.

MARTINS, Humberto Falcão. Burocracia e a revolução gerencial - a persistência da dicotomia entre política e administração. Revista do Serviço Público, v. 48, n.1, p.43-76, jan/abr. 1997.

OLIVEIRA, Isabel de Assis Ribeiro. Princípios de justiça e legitimação do Estado contemporâneo. Sociedade e Estado. n. 1, Jan/jun/97 p. 103 117, jan./jun jan/jun. 1997. v.XII. 
PINHO, José Antônio Gomes de, SANTANA, Mercejane Wanderley; CERQUEIRA, Sônia Margarida Bandeira. Gestão Pública em busca da cidadania: experiências de inovação em Salvador. Organizações \& Sociedade, v.4,n.8, p57-90, abr. 1997.

REIS, Elisa P. On citizenship. Paper presented at the XVII World Congress International

Political Science Association Seoul, Korea. August 17-21, 1997. 27 p. xerog.

- Governabilidade e Solidariedade. In: Governabilidade e pobreza no Brasil.

VALADARES Lícia, COELHO Magda P.(Orgs.). Rio de Janeiro: Civilização Brasileira,

1995. p. 49.63.

SANTOS, Guilherme Wanderley dos. Cidadania e Justiça: a Política social na ordem

brasileira.2a. ed. Rio de Janeiro: Campus, 1987. p. 64-75.

TEIXEIRA, Sônia Maria Fleury. Cidadania, Direitos Sociais e Estado. In: CONFERÊNCIA NACIONAL DE SAÚDE, 8, Anais. Brasília, 1987. p. $91-112$. 